\title{
A PRÁTICA COMO COMPONENTE CURRICULAR: TRADUÇÕES CURRICULARES
}

The practice as curricular component in pedagogy program: curricular translations La práctica como componente curricular en el curso de pedagogia: traducciones curriculares

Daniele Farias Freire Raic* Maria Roseli Gomes Brito de Sá**

Sirlândia Souza Santana***

Ubirajara Couto Lima****

https://doi.org/10.38117/2675-181X.formov2021.v3i1n5.303-324.

\section{Resumo}

Este artigo problematiza os contextos de produção das políticas para a formação de professores no Brasil, discute as traduções curriculares e apresenta uma proposição para a prática como componente curricular (PCC), trazida pela Resolução CNE n. 02/2015. Defende perspectivas curriculares em que teoria e prática se fundem, se atravessam e se complicam, como teoriaprática e anuncia a PCC como território de resistência, sobretudo, diante da Resolução CNE n. 02/2019. Trata-se de estudos realizados por professores de duas universidades baianas a partir de discussões e proposições do Núcleo Docente Estruturante (NDE) de um curso de Pedagogia. Parte das formulações dos ciclos de políticas proposto por Stephen Ball, suplementando-as com a ideia da tradução baseada em Derrida. Apoiandose em Deleuze e Foucault, discute a prática como luta contra o poder. Apresenta a PCC, denominada PP, como elemento integrador e articulador do currículo em sua potência formativa.

Palavras-chave: Formação de Professores; Traduções Curriculares; Teoriaprática; Prática como Componente Curricular.

\begin{abstract}
This article problematizes the contexts of production of politics to teacher training in Brazil, it discusses the curricular translations and presents a proposal to the practice as a curricular
\end{abstract}


component (PCC), brought by the CNE Resolution n. 02/2015. It defends perspectives in which theory and practice merge, intersect, and com-plicate, as theoripractice and annunciates the PCC as resistance territory, especially, facing the CNE Resolution n. 02/2019. It's about studies carried out by teachers from two Bahian universities starting with discussions and proposals of the Structuring Teaching Core (STC) form the Pedagogy program. It starts with the formulations of the political cycles proposed by Stephen Ball, supplementing with the idea of translation based on Derrida. It's supported in Deleuze and Foucautl, discussing the practice as a struggle against power. It presents the PCC, denominated Research and Practice $(\mathrm{RP})$, as integrating and articulating elements of curricula in its formative potency

Keywords: Teacher training; Curricular Translations; Theoripractice; Practice as Curricular Component.

\section{Resumen}

Este artículo problematiza los contextos de producción de las políticas para la formación de profesores en Brasil, discute las traducciones curriculares y presenta una propuesta para la práctica como componente curricular (PCC), acuñada por la Resolución CNE n. 02/2015. Defiende perspectivas en que la teoría y la práctica se funden, se atraviesan y se com-plican, como teoriapráctica y anuncia la PCC como territorio de resistencia, sobretodo, de cara a la resolución CNE n. 02/2019. Se trata de estudios realizados por profesores de dos universidades bahianas a partir de discusiones y propuestas del Núcleo Docente Estructurante (NDE) del curso de Pedagogía. Parte de las formulaciones de los ciclos de políticas propuesto por Stephen Ball, complementándolo con la idea de traducción basada en Derrida. Se apoya en Deleuze y Foucault, discute la práctica como lucha contra el poder. Presenta la PCC, denominada Pesquisa y Práctica (PP), como elemento integrador y articulador del currículo en su potencia formativa.

Palabras clave: Formación de Profesores; Traducciones Curriculares; Teoriaprática; Práctica como Componente Curricular

\section{Introdução}

As composições curriculares para a formação do pedagogo no Brasil têm sido motivo de importantes discussões em nossos cotidianos de trabalho e de produções acadêmicas. Ao longo dos anos, como pedagogas, pedagogos, professores e 
pesquisadores atuantes nos cursos de Pedagogia em universidades públicas ${ }^{1}$, temos acompanhado diferentes cenários políticos em que a formação dos profissionais da educação vem sofrendo muitos ataques, desde a formação inicial à atuação docente.

A partir de nossas experiências e dos debates que realizamos em nossas plenárias e nos grupos de pesquisa dos quais participamos, acompanhamos um esforço hercúleo em perspectivar e garantir a formação de professores cada vez mais qualificada nas universidades públicas, seja na graduação, seja na pós-graduação. Em comum aos nossos esforços temos a busca pela teoriaprática ${ }^{2}$ como um contínuo na atividade curricular. Essa vontade em pensar/propor currículos comprometidos com a formação no exercício da profissão é o que nos aproxima neste trabalho, produzido a partir de potentes encontros que temos experimentado como professores, como pesquisadores e como membros de comissões destinadas a proposições e atualizações curriculares. Quisemos com este texto, escrito a muitas mãos, problematizar os territórios de produções curriculares e, ao mesmo tempo, socializar nossas proposições, as quais colocamos como modos de resistência aos sucessivos desmontes da autonomia universitária e de sua liberdade intelectual.

O cenário político em que atualmente se encontra o Brasil está marcado por fortes tendências conservadoras e negacionistas, subjugado ao capitalismo neoliberal que tem se agravado (e se observado) mais notoriamente com o golpe político de 2016. Tal cenário tem nos convocado a um trabalho acadêmico engajado, no sentido de aglutinar forças em defesa da educação pública brasileira, de maneira geral, e da formação de professores/pedagogos, de modo particular. As políticas curriculares para a educação básica recaem sobre as políticas para a formação de professores como engrenagens discursivas que buscam colocar a formação docente como o centro dos vetores da qualidade da educação. Esse discurso, levado ao limite de suas problematizações, já sinaliza para controversos significados atribuídos à formação em si, que na maioria das vezes é entendida como a instrumentalização para aplicação de "modelos" pedagógicos.

Então, do nosso lugar de fala e de produção, nos autorizamos a i) problematizar os contextos de produção das políticas públicas para a formação de professores no Brasil; ii) discutir as traduções curriculares decorrentes das políticas de Estado para essa formação; e iii) apresentar uma proposição para a prática como componente curricular (PCC), uma vez que esta se constitui uma das diretrizes para as atualizações curriculares

\footnotetext{
1 Este trabalho foi realizado com a participação de uma professora da Faculdade de Educação da Universidade Federal da Bahia (FACED/UFBA) e três professores da Universidade Estadual do Sudoeste da Bahia (UESB), pesquisadores nos campos de políticas da educação e de currículos, que mantém aproximações teoricopráticas através dos grupos de pesquisa dos quais são membros.

${ }^{2}$ Recorremos à fusão dos temos na escrita a fim de ratificar a unidade da teoria e da prática na formação docente.
} 
dos cursos de formação de professores trazidas pela Resolução CNE 02/2015, documento que defendemos como principal ancoragem atualmente para a formação de professores brasileiros.

Assim, assumindo a natureza das pesquisas implicadas, afirmamos o nosso desejo de anunciar perspectivas curriculares em que teoria e prática se fundem, se atravessam e se com-plicam ${ }^{3}$ e, então, propomos discutir e anunciar a prática como componente curricular (PCC) enquanto um território de resistência (e de luta) ao esvaziamento político da formação de professores no Brasil, provocado sobretudo pela Resolução CNE/CP n ${ }^{\circ}$. 02/2019, que define as Diretrizes Curriculares Nacionais para a Formação Inicial de Professores para a Educação Básica e institui a Base Nacional Comum para a Formação Inicial de Professores da Educação Básica (BNC-Formação) e revoga a Resolução CNE/CP 02/2015.

Este texto é resultado de estudos, discussões e proposições realizadas a partir do Núcleo Docente Estruturante (NDE) durante o período de 2019 a 2020, da Universidade Estadual do Sudoeste da Bahia, campus de Jequié, quando foram intensificados os trabalhos da comissão para a atualização curricular do curso de Pedagogia, em atendimento à Resolução CEE n. 70, de 16 de julho de 2019, que regulamenta a implantação das Diretrizes Curriculares Nacionais para a Formação Inicial em Nível Superior, nos Cursos de Graduação de Licenciatura, mantidos pelas instituições de ensino superior integrantes do Sistema Estadual de Ensino da Bahia, em conformidade com a Resolução CNE/CP n. 02/2015. Importa destacar que, em nossa leitura, a Resolução do CEE significou resistência à movimentação do CNE em adotar um modelo de formação técnico-instrumental e prescritivo, que se traduziria com a Resolução CNE/CP n. 02, de dezembro de 2019.

Entretanto, o que apresentamos não se configura um relato de experiência do NDE; antes, o que trazemos são problematizações e proposições decorrentes de nossos estudos sobre os tensionamentos que emergem dos processos de atualizações curriculares, sobretudo, quanto ao entendimento acerca da prática como componente curricular (PCC). São traduções realizadas a partir dos fóruns de licenciatura, dos grupos de pesquisa, de lives realizadas por entidades que discutem a formação de professores no Brasil, dentre outros espaços de discussões e debates. Ao torná-lo público, nossa pretensão é que este trabalho se some aos diversos estudos e movimentos que buscam a garantia da formação

\footnotetext{
${ }^{3}$ Partimos do pressuposto que teoria e prática implicam-se tanto entre si, quanto com seus contextos de produção.
} 
de professores alinhada aos princípios políticos em defesa da educação como um bem público, quando forças contrárias insistem em se impor.

Como ponto de partida para a problematização que ora pretendemos com este texto, consideramos o ciclo de políticas proposto por Ball e Bowe (1992) e trabalhado, no Brasil, entre outros, por Mainardes (2006), Lopes, Cunha e Costa (2013). Ao discutir a reforma educacional inglesa de 1988, os citados Ball e Bowe propõem uma matriz de análise das políticas educacionais que se afaste do modelo de controle do estado e considere o processo como um ciclo de política em que os textos dos documentos legais sejam vistos como um documento de trabalho passível de ser interpretado por políticos, professores, [alunos, diríamos], sindicatos e outros setores interessados, "traduzindo essa legislação em práticas cotidianas” (BALL; BOWE, 1992, p. 98. Tradução nossa). Esse ciclo comportaria um processo contínuo constituído por três contextos: 1) o contexto de influência, que se refere onde/quando os discursos são produzidos, de maneira que os interesses são tensionados para influenciar a definição das finalidades das políticas; 2) o contexto da produção do texto, ligado ao contexto anterior e, também atravessado por conflitos, refere-se à busca de um suposto consenso em torno dos textos legais, documentos oficiais, pronunciamentos oficiais etc, em que são incorporados os discursos considerados legítimos; e 3) o contexto da prática, interrelacionado aos anteriores, mas, em seus desdobramentos, sujeito à interpretação e à recriação, pois, como afirma Mainardes (2006, p. 97), “os textos das políticas terão uma pluralidade de leituras devido à pluralidade de leitores". Em estudos posteriores, como nos informa Mainardes (2006), Ball acrescentou aos três contextos, aqui brevemente apresentados, outros dois: 1) o contexto dos resultados, considerado como os efeitos das políticas, analisadas à luz dos impactos e das interações com as desigualdades existentes, por isso preocupado também com as questões de justiça, de igualdade e de liberdade individual; e 2) o contexto da estratégia política que, por sua vez, constitui a identificação de um conjunto de atividades sociais e políticas necessárias que devem lidar com os problemas identificados, quer sejam criados ou reproduzidos pela própria política.

Esses contextos pensados por Ball e Bowe nos ajudam a situar o curso de Pedagogia considerando os ciclos de suas políticas, em uma abordagem complexa, colocando-nos em movimentos dialógicos frente a algumas questões provocativas: a partir de quais contextos de influência a Pedagogia vai, de tempos em tempos, sendo (re)pensada? Quais os contextos de produção dos textos (marcos legais) que vão de certa maneira definindo o que "pode" o pedagogo em diferentes cenários? Como as universidades e seus currículos vão traduzindo as políticas para o curso de Pedagogia? Quais os contextos de efeitos dessas políticas, considerando as traduções curriculares? 
Entretanto, ainda que tenhamos partido da ideia dos ciclos de políticas que de certa forma se ancoram na noção de recontextualização inicialmente trabalhada por Ball com inspiração em Bernstein (2003), mas acrescida da ideia do hibridismo, concordamos com Lopes, Cunha e Costa (2013, p. 396) que "a noção de recontextualização por hibridismo, de transferência de sentidos entre contextos, [...] tende a desconsiderar, na análise das mudanças sociais, as relações entre estruturas simbólicas e sociais”. Então, por concordarmos com as provocações feitas pelos autores, seguimos neste texto em direção à ideia de tradução, uma vez que,

\begin{abstract}
A noção de tradução, como a possibilidade de relação entre a linguagem e os objetos que ela nomeia, torna-se potente aos estudos das políticas de currículo ao permitir questionar a noção de representação plena advogada pelos críticos das políticas que cobram sentidos coerentes das práticas, por quem atua (em algum nível) na elaboração de documentos assinados por governos e que, de algum modo, crê que os textos expressem a exata correlação ou correspondência entre o escrito e suas demandas (LOPES; CUNHA; COSTA, 2013, p. 398, grifo dos autores)
\end{abstract}

A decisão de assumir para este trabalho a noção de tradução se encontra com a nossa compreensão de currículo como linguagem. E, sendo linguagem, o currículo é uma prática social tramada a partir de diversas traduções, comportando também as intraduzibilidades, como argumentaremos ao longo deste texto, organizado em quatro seções.

Na primeira seção fazemos uma breve digressão histórica sem, contudo, ter a intenção de fazer um tratado histórico do curso de Pedagogia no Brasil. Essa opção por uma imersão histórica se justifica por acreditarmos que nenhuma política curricular seja "pura", "neutra" ou "indiferente" em relação às anteriores. Na segunda seção nos dedicamos à problematização das traduções curriculares, quando nos aproximamos de Derrida e de seus interlocutores, bem como dos possíveis deslocamentos do conceito derridiano de tradução para as políticas curriculares. Na terceira seção apresentamos uma proposição para a PCC no curso de Pedagogia, produzida a partir dos nossos embates e dilemas, cuja arquitetura curricular possa favorecer a teoriaprática como princípio do exercício formativo para os estudantes da Pedagogia. E por fim, sem pretender a finitude da discussão, mas na tentativa de produzir traduções outras, apresentamos nossas considerações sobre as necessárias resistências aos ataques à formação de professores no Brasil, daí nossa vontade que essa seção não seja tratada pelo leitor como "finais". 


\section{O curso de Pedagogia no Brasil}

Fazer um retorno aos processos históricos que vêm constituindo o curso de Pedagogia no Brasil é um modo de acompanharmos alguns discursos legais ao longo nos anos. Criado pelo Decreto $\mathrm{n}^{\circ} 1.190$, de 04 de abril de 1939, esse curso recebeu sua "certidão de nascimento" num contexto bastante pantanoso, carregado de muitas imprecisões. De acordo com o referido decreto, o curso de Pedagogia voltava-se para formar bacharéis e licenciados para várias áreas, numa formatação curricular conhecida como 3+1, ou seja, três anos para a formação em bacharelado e um ano para a formação do licenciado, após o curso de didática. Para o pedagogo bacharel ficava a função de técnico da educação e ao licenciado a docência na Escola Normal (responsável pela formação de professores primários) e no ensino secundário. Sobre essa questão, Saviani (2007, p. 118) atenta que o Decreto-Lei n ${ }^{\circ} 1.190 / 1939$, “em lugar de abrir um caminho para o desenvolvimento do espaço acadêmico da pedagogia, acabou por enclausurá-lo numa solução que se supôs universalmente válida em termos conclusivos", uma vez que o curso formava o bacharel e o licenciado, mas não definia o que deveria fazer um técnico da educação e nem mesmo quais as matérias que deveria ensinar.

Silva (2006) adverte para um curso que desde suas origens está atravessado por fragilidades e inadequações, facilmente percebidas na própria definição de um currículo direcionado à formação de um profissional não claramente definido. Para a autora, essa inadequação se mostra em três principais tensões: 1) de natureza de campo de atuação, pois, por um lado, tinha-se a expectativa do exercício de funções técnicas a serem realizadas pelo bacharel e, de outro, pelo caráter generalista das disciplinas fixadas pela sua formação; 2) a separação bacharelado-licenciatura, refletindo a dicotomia do tratamento com o trabalho pedagógico, ou seja, o conteúdo e o método. Ao referir-se ao Decreto-lei $\mathrm{n}^{\circ}$ 8.530/46, da Lei Orgânica do Ensino Normal, a autora adverte que para lecionar nesse curso bastava possuir o curso superior, demonstrando, ainda mais, quanto estava difuso o campo de atuação do pedagogo, já que a este cabiam as matérias de filosofia, história e matemática.

Esses primeiros atos legais estavam sintonizados com a própria noção de ciência e de trabalho pedagógico da época, cuja perspectiva de formação estava direcionada ao campo prático do trabalho educativo, cuja ideia de prática estava associada à de aplicação. Em 1962 o Conselho Federal de Educação, através do Parecer no 251/1962, alterou a proposta para a formação de pedagogos, estabelecendo o currículo mínimo e a duração do curso de Pedagogia, até então não previstas. Entretanto, segundo Cruz (2011), o curso de Pedagogia continuou dividido entre bacharelado e licenciatura, formando o técnico ou especialista de educação e o docente para as disciplinas do Curso Normal. Quanto à 
Daniele Farias Freire Raic, Maria Roseli Gomes Brito de Sá, Sirlândia Souza Santana e Ubirajara Couto Lima

questão da duração do curso, a mudança sensível se deu por ser possível cursar as disciplinas das licenciaturas concomitantemente com as do bacharelado, não mais sendo necessário esperar o quarto ano.

Em 1969, após a reforma Universitária n $\mathrm{n}^{\circ}$ 5.540, de 28 de novembro de 1968, o curso de Pedagogia foi impactado legalmente pelo parecer no 252/69 do Conselho Federal de Educação (CFE), de autoria de Valnir Chagas (o mesmo que fizera o Parecer CFE $\mathrm{n}^{\circ}$ 251/1962), do qual resultou a Resolução CFE nº. 2/69. Esse novo ato legal instituiu as habilitações para o curso de Pedagogia, formando os "especialistas" nas quatro modalidades indicadas (Orientação Educacional, Administração Escolar, Supervisão Escolar e Inspeção Escolar) e, ainda, o professor para o ensino normal (SAVIANI, 2007).

No seio das discussões sobre a Resolução CFE nº. 2/69, Cruz (2010) acrescenta, ainda, que esse marco legal aboliu o grau de bacharel em Pedagogia, prevalecendo apenas o de licenciado, de modo que para alcançar uma habilitação o candidato deveria comprovar sua experiência de magistério.

Há, ainda, um movimento que marca a trajetória do curso de Pedagogia no Brasil inaugurado pelo Comitê Pró-Participação na Reformulação dos cursos de Pedagogia e Licenciatura. Esse comitê instituiu a Comissão Nacional de Reformulação dos Cursos de Formação do Educador (CONARCFE), que em 1990 transformou-se na Associação Nacional pela Formação dos Profissionais da Educação (ANFOPE). Esta entidade coloca a docência como base da formação do educador, cuja ideia tem centralidade em muitas propostas curriculares para o curso de Pedagogia, destacando-se, sobretudo, a formação para a docência na educação infantil, nos anos iniciais do ensino fundamental, na educação de jovens e adultos e na educação especial.

Sem dúvidas, esses movimentos parecem ter culminado na Resolução CNE $\mathrm{n}^{\mathrm{o}} .01 / 2006$, que institui as Diretrizes Curriculares para o curso de Pedagogia, quando finalmente a docência aparece como centralidade da formação. Ao assim proceder, as políticas públicas para a formação de professores recaem, também, sobre os seus currículos. É assim que a Resolução CNE/CP nº.02/2015, que define as Diretrizes Curriculares Nacionais para a formação inicial em nível superior (cursos de licenciatura, cursos de formação pedagógica para graduados e cursos de segunda licenciatura) e para a formação continuada, impacta e convoca as atualizações curriculares dos cursos de Pedagogia. 
A Resolução CNE nº 02/2015, fruto de longos e profícuos debates travados pelas comunidades acadêmicas do país, normatizou determinadas demandas dos cursos de licenciatura no Brasil que já se arrastavam há décadas (DOURADO, 2015), tais como:

I. Sólida formação teórica e interdisciplinar dos profissionais;

II. A inserção dos estudantes de licenciatura nas instituições de educação básica da rede pública de ensino, espaço privilegiado da práxis docente;

III. O contexto educacional da região onde será desenvolvido;

IV. Atividades de socialização e avaliação dos impactos;

V. Aspectos relacionados à ampliação e ao aperfeiçoamento do uso da língua portuguesa e à capacidade comunicativa, oral e escrita, como elementos fundamentais da formação dos professores e à aprendizagem de Libras;

VI. Questões socioambientais, éticas, estéticas e relativas a diversidade étnico-racial, de gênero, sexual, religiosa, de faixa geracional e sociocultural como princípios de equidade. (DOURADO, 2015, p. 306)

A referida resolução abriu capítulo importante para as universidades públicas brasileiras, uma vez que, embora possamos afirmar o avanço dessa conquista legal, somente foi promulgada num momento em que o cenário político brasileiro se encontrava bastante pantanoso. Enfrentávamos as correlações de forças políticas que culminariam com o golpe de 2016, com o impeachment da presidenta Dilma Rousseff, do Partido dos Trabalhadores (PT). Decorrem do golpe profundas instabilidades políticas com a assunção de Michael Temer (PMDB ${ }^{4}$ ) como presidente da República. As universidades, então, sofrendo os mais diversos ataques em seus orçamentos, somados às emergências de discursos que insistem em minar a autonomia e a atuação das universidades públicas brasileiras, viram-se convocadas mais aos atos políticos em defesa da universidade pública e menos ao engajamento nas atualizações curriculares para os cursos de formação de professores. Resulta disso o início tardio das atualizações curriculares para as licenciaturas no Brasil, aumentando seus desafios a partir de 2019, com a revogação da Resolução CNE/CP n. 02/2015, pela Resolução CNE/CP n. o 02/2019.

\section{Traduções curriculares}

As discussões sobre políticas de currículo são de grande interesse entre os pesquisadores brasileiros. Há, contudo, importante destaque para os estudos realizados na Universidade Estadual do Rio de Janeiro (UERJ), amplamente difundidos no campo do currículo. Esses estudos começaram tomando como inspiração o ciclo de políticas

\footnotetext{
${ }^{4}$ Partido do Movimento Democrático Brasileiro
} 
proposto por Stephen Ball e Bowe, dentre outros, que trabalham com a ideia de contextos, no lugar da recontextualização como propunha Basil Bernstein, autor que inspirou as primeiras formulações críticas de Ball nesse campo. Ao trazer a ideia dos contextos (de influência, da formulação de textos e da prática, depois acrescidos pelos contextos dos efeitos e de estratégias políticas), Ball e demais autores saíram de uma leitura mais estruturalista feita por Bernstein ${ }^{5}$. Para Bernstein, as propostas de currículo procuram veicular conhecimentos a partir de determinados códigos, mas, por mais controle que se pense imprimir, há sempre uma recontextualização. Entretanto, em que pese o alcance de seu trabalho, ele não consegue sair da relação de poder centralizado "no alto", estrategicamente colocado como "poder sobre". Ball, por sua vez, tenta estabelecer um ciclo, considerando que em quaisquer contextos as proposições políticas poderão ser mexidas, hibridizadas. O "local" pode "mexer" com o global, e assim, as propostas se hibridizam. Na sequência de seus estudos, Ball vai incorporando referenciais pósestruturalistas e começa a questionar inclusive a própria ideia de implementação, a qual supõe a presença de um consenso e, assim, ao pressupor as políticas como construtoras de consensos, evoca uma harmonia que, a rigor, não existe.

O movimento de implementação de políticas pode ser caracterizado como a expressão de consentimento com a proposta sugerindo, através de seus argumentos, que se pode eliminar o que é discordante quando as políticas "globais" são implementadas nas esferas "locais".

Nós, atravessados por nossos intercessores ${ }^{6}$, dizemos que as políticas se dão também no âmbito da linguagem, das tramas discursivas, dos jogos de poder e o texto expresso no documento resulta dessas tramas, desses jogos que são operados nos diversos contextos, se formos falar de Stephen Ball.

A política é tramada nesses diversos contextos e a multiplicidade de vozes pode deslocar a centralidade dos discursos. Há uma multiplicidade de traduções possíveis brigando entre si e levando a ações políticas. De acordo com Lopes, Cunha e Costa,

A tradução comparece na percolação incessante da discursividade, viabiliza o surplus de sentido sobre os objetos da educação. Educar, ensinar-aprender, formar/ar os professores/as, adequar estratégias metodológicas, inovar a avaliação, flexibilizar o conhecimento,

\footnotetext{
${ }^{5}$ Bernstein muito contribuiu para as discussões sobre as relações de poder e controle nos currículos no início dos anos 1970 puxadas por Michael Young que depois se constituíram em um novo campo sociológico, a Nova Sociologia da Educação (NSE)

${ }^{6}$ Os intercessores para Deleuze (2013) são todos aqueles ou tudo aquilo com quem/que nos encontramos e quem/que nos atravessam, nos compõem e nos fazem em multiplicidades.
} 
humanizar a relação professor/aluno/conhecimento, melhorar a qualidade da educação, dentre outros, são termos que podem ocupar um ponto nodal de articulação entre distintos projetos educativos/societários. São significantes/superfícies de inscrição em que são operados/as equivalências produzidas no todo diferencial. (LOPES; CUNHA; COSTA, 2013, p. 400, grifos dos autores)

O uso da tradução no campo do currículo vem da entrada dos estudos pós-críticos sobre o referido campo, quando diferentes críticas se impõem aos limites até então não ventilados pelas teorias críticas em educação. Os estudos das teorias pós-críticas do currículo advêm de referenciais de vários matizes, os quais questionam dentre outras coisas, o fim das utopias e das certezas, a ideia de verdade. Ao mesmo tempo, vê emergir as demandas particulares e as lutas da diferença, da aceleração das trocas culturais e dos fluxos globais e da compressão espaço-temporal (LOPES, 2013). Dentre essas abordagens, destacamos as contribuições de Derrida, considerado um filósofo da desconstrução, a quem recorremos para discutir que um texto legal não traduz as intencionalidades de quem os produziu e, tampouco será implementado, face à sua intraduzibilidade.

Derrida (2006) retoma o clássico texto de Benjamin sobre a tarefa do tradutor observando que, mais do que tratar do problema da tradução, o mais significativo nesse escrito é o fato do sujeito da tradução ser nomeado como "sujeito endividado, obrigado por um dever, já em situação de herdeiro, inscrito como sobrevivente dentro de uma genealogia, como sobrevivente ou agente de sobrevida. A sobrevida das obras, não dos autores" (DERRIDA, 2006, p. 32). Dá-se, portanto, uma nova dimensão à obra, uma sobrevida que não é determinada apenas pela técnica da tradução propriamente dita, mas também dos seus efeitos, digamos assim.

Se estamos tratando de uma multiplicidade de vozes na trama e na interpretação das políticas, a tradução passa a ser um elemento fundante e a quebra da superioridade da autoria, no caso aqui, da supremacia dos textos legais, abre a possibilidade de interpretações e de proposições diferenciadas de ações. Não há texto legal que seja traduzido em sua biunivocidade, nos contextos em que se efetivam. Traduzir não supõe, nessa perspectiva, uma única interpretação. A tradução é antes, uma intradução, como vai nos dizer Derrida ao longo de sua obra.

Ao escrever sobre a Torre de Babel, passagem bíblica que produz variados significados, Derrida (2006) questiona a ideia vulgar da tradução como confusão, pela alusão à pretensa unificação das línguas e a posterior impossibilidade de tal unificação imposta como um castigo. Ironizando diversas interpretações possíveis, Derrida discute a abertura e mesmo a necessidade de tradução de um texto original a partir também de 
impossibilidades de uma tradução literal, dada a "babelização" da linguagem em suas múltiplas manifestações. Há nessas formulações um descentramento dos sujeitos da enunciação, da interpretação, da tradução, assim como estamos defendendo o descentramento das traduções das políticas. Para Lopes, Cunha e Costa, citando Derrida,

Toda tradução, portanto, é uma produção original que, ao ser desencadeada, ainda que o tradutor pretenda se reconciliar com um suposto sentido anterior, ela já o corrompeu, cabendo-lhe à suplementação como sentença final, como possibilidade de expressão e continuidade. Por essa razão, Derrida (2006) afirma que o texto vive uma regeneração constante pela tradução, o que sustenta a ideia de que toda tradução não passa de uma tentativa de aliança e de uma promessa. Essa tarefa impossível, ao mesmo tempo em que imputa ao tradutor uma culpabilidade infinita, também o absolve instantaneamente, pois não se pode fazer mais nem menos do que se faz. (LOPES; CUNHA; COSTA, 2013, p. 403-4, grifos dos autores)

É, pois, na tentativa de reconciliação com o texto original que nos dispusemos ao trabalho de atualização curricular para o curso de Pedagogia. Todavia, em nossas negociações, vimo-nos corrompendo os textos oficiais; experimentamos as suas intraduzibilidades. E, ao tentarmos traduzir a ideia de Prática como Componente Curricular, nos colocamos diante da "tarefa impossível". A questão que se impõe às atualizações curriculares é profundamente com-im-plicada ${ }^{7}$. Um currículo é produzido na imanência das vozes, das práticas, dos sentidos, dos desejos. Um texto legal, como já dissemos, não é capaz de exprimir o consenso. Não se trata de "entender" o que diz a "lei"; é uma questão de tradução. É assim que apresentamos a seção a seguir: como uma suplementação, de quem "não se pode fazer mais nem menos do que se faz".

\section{A prática como Componente Curricular (PCC): traduções em torno da teoriaprática}

A Resolução n ${ }^{0}$. CNE/CP 02/2015, acerca da incorporação da PCC ao longo do processo formativo dos licenciandos, se coloca para nós como o maior desafio aos nos lançarmos em perspectivar a sua operacionalidade. De acordo com Luiz Dourado,

[...] deverá ser garantida, ao longo do processo, efetiva e concomitante relação entre teoria e prática, ambas fornecendo elementos básicos para

\footnotetext{
${ }^{7}$ Chamamos de com-im-plicado todo o movimento de produção curricular. Se os autores curriculantes são sujeitos implicados com o que produz, estão, ao mesmo tempo implicados com os seus intercessores. Essa expressão é uma tentativa nossa de afirmar uma imagem calesdoscópica para a tradução.
} 
o desenvolvimento dos conhecimentos e habilidades necessários à docência. Importante apreender tais processos e, sobretudo, situar a concepção e o entendimento do papel da prática como componente curricular e do estágio supervisionado, resguardando a especificidade de cada um e sua necessária articulação, bem como a necessária supervisão desses momentos formativos (DOURADO, 2015, p. 309$310)$.

A questão da unidade entre teoria e prática, a teoriaprática como temos chamado, é uma demanda antiga. Entretanto, não há uma resposta que dê conta de significar a questão: o que é a prática? A prática é um dos termos polissêmicos que nos lançou em diversos horizontes semânticos. Em nossas andanças, a fim de melhor compreender de que tratava a Resolução CNE nº 02/2015, nos deparamos com muitas proposições curriculares; vimos que numa mesma instituição, diferentes cursos a tinham por sentidos diversos.

Que suplementação fizemos para a PCC? Sobre isso, fazemos alguns esclarecimentos. Do ponto de vista da sua finalidade, entendemos que a PCC propõe fortalecer a indissociabilidade teoriaprática. Nesse sentido, buscamos em um diálogo de Deleuze e Foucault (DELEUZE, 2006), em que Deleuze assim responde a uma provocação de Foucault:

Talvez seja porque estejamos vivendo de maneira nova as relações teoria-prática. Às vezes se concebia a prática como uma aplicação da teoria, como uma consequência; às vezes, ao contrário, como devendo inspirar a teoria, como sendo ela própria criadora para uma teoria vindoura. De qualquer modo, suas relações eram concebidas como um processo de totalização, num sentido ou noutro. Talvez, para nós, a questão se coloque de outra maneira. As relações teoria-prática são muito mais parciais e fragmentárias. Por um lado, uma teoria é sempre local, relativa a um pequeno domínio, e pode ter sua aplicação em outro domínio, mais ou menos afastado. A relação de aplicação nunca é de semelhança. Por outro lado, desde que a teoria penetre em seu próprio domínio, encontra obstáculos, muros, choques, que tornam necessário que ela seja revezada por outro tipo de discurso (é este outro tipo que permite eventualmente passar a um domínio diferente). A prática é um conjunto de revezamentos de um ponto teórico a outro, e a teoria um revezamento de uma prática a outra. Teoria alguma pode se desenvolver sem encontrar uma espécie de muro, e é preciso a prática para atravessar o muro. (DELEUZE, p. 265).

A concepção de prática que Deleuze nos apresenta é um convite a perspectivarmos novos sentidos à PCC. Se, em algum momento, ela teve por intenção um contexto de aplicação das teorias "aprendidas" ao longo da formação, agora, considerando a prática como um conjunto de revezamentos da teoria, capaz de atravessar os próprios "muros" em que as teorias se chocam, podemos traduzir a PCC como esse 
movimento contínuo de lançar-se e atravessar os muros. A PCC, então, é esse espaço potente de formação que os currículos oficiais vêm desprezando, uma vez que ainda coloca a prática (assim como o estágio) como territórios de aplicação, ou mesmo de inspiração para a teoria, como bem nos disse Deleuze. Queremos, pois, pensar a prática em toda a sua potência formativa, apesar dos muros em que nós, nos movimentos de alterações curriculares, nos chocamos.

Apresentados os esclarecimentos sobre o que afirmamos como teoriaprática, buscamos aproximar as interfaces das disciplinas como territórios de saberes e de conhecimentos, a fim favorecer uma fecunda articulação entre as PCC e os Estágios (aqui também entendidos como campo de produção de conhecimentos), a pesquisa e extensão. Para tanto, o que propomos para as PCC é uma imersão dos licenciandos em seus mundos formativos de maneira que possam produzir e mobilizar conhecimentos propostos pelo currículo instituído, mas, sobretudo, apesar dele.

A PCC, no sentido que perspectivamos, também é um espaço que permita ao licenciando colocar-se à espreita do que lhe possa acontecer, em intensa conexão entre os conhecimentos acadêmicos escolares e não escolares, a ambiência escolar ou não escolar, de natureza educativa. Com essa perspectiva em mente, ao invés de se afirmar como um espaço de observação e aplicação, propomos que a PCC seja o elemento integrador e articulador do currículo, capaz de se constituir com toda a sua potência formativa nos encontros decorrentes dos trânsitos entre a Universidade, a Escola e outros Espaços Educativos.

Importa sublinhar a essa altura que a recomendação do Parecer $\mathrm{CNE} / \mathrm{CP} \mathrm{n}^{\circ}$. 02/2015, a define como um

[...] conjunto de atividades formativas que proporcionam experiências de aplicação de conhecimentos ou de desenvolvimento de procedimentos próprios ao exercício da docência. Por meio destas atividades, são colocados em uso, no âmbito do ensino, os conhecimentos, as competências e as habilidades adquiridos nas diversas atividades formativas que compõem o currículo do curso. As atividades caracterizadas como prática como componente curricular podem ser desenvolvidas como núcleo ou como parte de disciplinas ou de outras atividades formativas. Isto inclui as disciplinas de caráter prático relacionadas à formação pedagógica, mas não aquelas relacionadas aos fundamentos técnico-científicos correspondentes a uma determinada área do conhecimento (BRASIL, 2015, p.3).

Todavia, em nossas traduções, no exercício das negociações com o texto legal, assumindo que a teoriaprática é um movimento não totalizante, assumimos a aplicação 
das teorias em domínios parciais e fragmentários, em revezamentos com a prática, em que teoria e prática são movimentos de produção, de criação, de inventividade na feitura de conhecimentos outros, também provisórios. Retomando ao diálogo de Deleuze e Foucault (DELEUZE, 2006, p. 267), este, concordando com aquele, assim nos diz: “[...] a teoria não expressará a prática, não traduzirá, não aplicará uma prática; ela é uma prática". E, ao assim dizer, Foucault coloca a teoria como um sistema de luta contra o poder. Assim, a fim de escapar das armadilhas da teoria e prática como produção de verdade totalizante e de aplicação, respectivamente, e, considerando a potência da PCC como espaço de pesquisas, decidimos chamá-la na arquitetura curricular de Pesquisa e Prática (PP), que pode ser visualizada na Figura 1.

Figura 01 - Arquitetura Curricular Curso de Pedagogia.

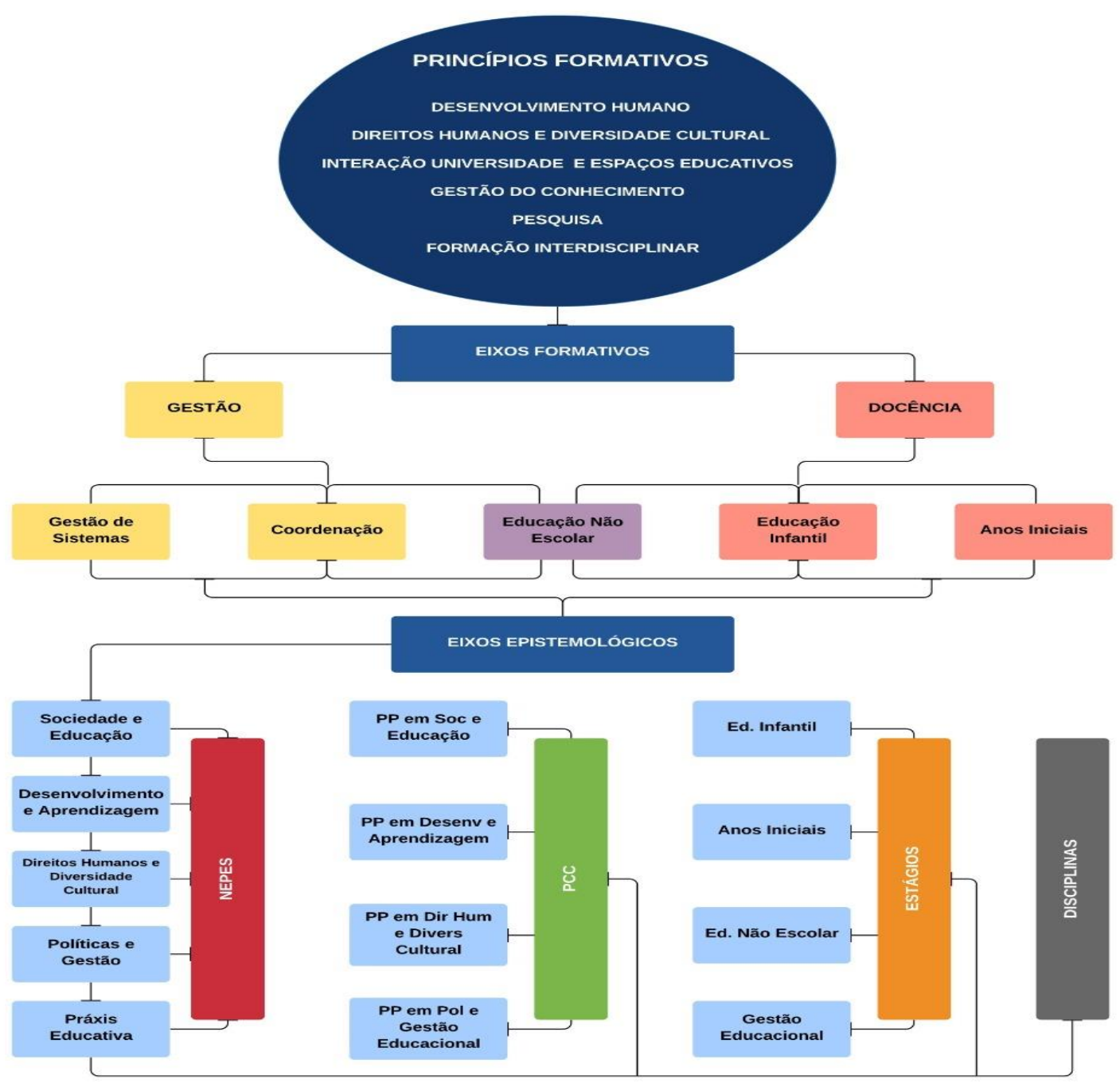

Fonte: Núcleo Docente Estruturante - NDE, Curso de Pedagogia. 
Em nossas composições, buscamos um desenho que, inicialmente, deixasse ver os princípios formativos que deveriam conduzir à formação dos pedagogos. Feito isso, coletivamente, definimos alguns dos campos de atuação do pedagogo, sobre os quais foram traçados os percursos formativos, quais sejam: a docência e a gestão, tanto na educação escolar quanto na educação não escolar. Daí, a comissão se debruçou em propor os eixos epistemológicos em torno dos quais foram criados os Núcleos de Estudos, Pesquisa e Extensão (NEPE). Os NEPE são unidades que inspiram, alimentam as PP e as nomeiam, inclusive. A figura a seguir é um esforço que ora fazemos para pensar na institucionalização da PCC no curso de Pedagogia, campus de Jequié-BA.

Uma das questões sobre as quais os autores curriculantes (coletivo de docentes e discentes) buscaram manter em seus discursos volta-se para a reflexão crítica permanente como orientação para a formação inicial dos estudantes da pedagogia, tendo em vista promover atualizações no cenário pedagógico através de suas práxis educativas, pois, "a prática docente crítica [...] envolve o movimento dinâmico, dialético, entre o fazer e o pensar sobre o fazer. [...] Precisa é possibilitar, que, através da reflexão sobre a prática, a curiosidade ingênua, percebendo-se como tal, se vá tornando crítica" (FREIRE, 2001 p. 42-43). Inclusive, como pode ser notado na figura 1, a práxis educativa é o NEPE que inspira os estágios. Esses, por sua vez, devem superar a visão reducionista de campo de aplicação e segue em direção à sua constituição de um fazer pedagógico teóricoprático que, à escolha dos membros do Colegiado do Curso de Pedagogia (CCP), deve estar alinhado à uma perspectiva histórico-cultural, de aporte sobretudo, freireano.

Essa proposição apresentada na figura 01 contou com muitos impasses, uma vez que para muitos docentes a PCC deveria fazer parte de uma carga horária da disciplina em que os licenciandos aprofundam os conceitos da própria disciplina. Essa compreensão de prática dificultou, como observamos em nossas negociações, a emergência da PP como eixo integrador curricular. Por outra via, em nossa tradução, dizemos que tal interpretação reduz a prática à aplicação, ainda que defendamos que as disciplinas devem ter uma creditação prática para fins de aprofundamento conceitual/teórico, indispensável à formação. Entendemos que a carga horária prática constante nas disciplinas se deve aos saberes relativos às especificidades próprias da constituição dos objetos de conhecimento de cada campo disciplinar, mas, em si, não promovem a imersão do estudante da pedagogia em seus campos de atuação, os quais estão prioritariamente vinculados à constituição da profissionalidade do pedagogo, quer seja na Educação Básica, quer seja em outras ambiências educativas em que requeira a atuação do pedagogo. 
Acerca desse aspecto, retornamos ao Parecer CNE/CES n ${ }^{\circ}$ 15/2005, que responde consulta feita pela UESB e esclarece, à época, sobre as Resoluções CNE/CP nº 1/2002, que institui Diretrizes Curriculares Nacionais para a Formação de Professores da Educação Básica, em nível superior, curso de licenciatura, de graduação plena, e 2/2002, que institui a duração e a carga horária dos cursos de licenciatura, de graduação plena, de Formação de Professores da Educação Básica, em nível superior. O referido parecer, desde então, já deixa ver que a PCC não deveria ser destinada às áreas alusivas aos fundamentos técnico-científicos e explica: “disciplinas de caráter prático em Química, cujo objetivo seja prover a formação básica em Química, não devem ser computadas como prática como componente curricular nos cursos de licenciatura" (BRASIL, 2005, p. 3).

Desse modo, defendemos que as PCC devem estreitar as relações entre a Universidade e as ambiências educativas, como espaços de produção e criação de saberes e conhecimentos. As atividades de PP, como as que propomos, devem estar organizadas a partir de situações observadas nas dinâmicas das culturas escolares e não escolares, em seus mais variados espaços, inclusive pela mediação das Tecnologias da Informação e Comunicação (TIC). Para nós, a PP deve expandir seus domínios escolares (território já posto quando falamos das licenciaturas) e incorporar a multiplicidade que envolve os diversos sistemas que promovam ações educativas, tais como o Sistema Prisional, as classes hospitalares; os programas de atendimento às crianças e jovens em situações de vulnerabilidade social, o Centro de Referência Especializado de Assistência Social (CREAS), o Centros de Referências de Assistência Social (CRAS) ou quaisquer outros que requeiram a presença de um pedagogo, como profissional dedicado à teoriaprática da educação como luta contra o poder, como nos disse Foucault.

\section{Algumas notas frente à operacionalização da PP}

Como já dissemos, a PP é inspirada pelos NEPE e organizadas a partir dos eixos epistemológicos (Figura 1). Com isso, defendemos que o professor articulador de cada PP seja também membro de um NEPE e que sua atuação nas PP seja por sistema de revezamento com os demais membros do núcleo, a cada semestre, priorizando as linhas de pesquisa e extensão que constituem os NEPE e as PP. A preocupação que se impôs aos membros do NDE é que aconteça uma disciplinarização da PP o que, certamente, minaria a proposta de ser um elemento integrador e articulador do currículo. Se a PCC não pode ser tratada como carga horária prática de uma disciplina, tampouco pode ser tratada como uma disciplina. Esse para nós é o maior desafio. 
Em nossas negociações com os colegas, ao problematizarmos a PCC, alguns professores, sobretudo dos campos de fundamentos da educação, viram-se impedidos de participar da PP por considerarem que suas disciplinas não são "práticas", deixando óbvio que ainda a veem como aplicação. Esses "nós" sugestivos de impasses despertam em nós alguns alertas: como pensarmos uma prática curricular capaz de superar essa visão reducionista de prática? Como agenciar forças capazes de institucionalizar um currículo em que a teoriaprática seja um princípio formativo?

Tais questões são impossíveis de respostas, vez que a institucionalização curricular, através de um Projeto de Curso, é também intraduzível. Ainda assim, sabendo que a tradução é uma trama (in)tensa, arriscamos em apontar algumas possibilidades, retiradas de nossos movimentos curriculantes. Nesse sentido, mesmo sabendo que todo projeto curricular é corrompido ao ser traduzido, a fim de tentar posicionar a PP o mais próximo do que pensamos, atentamos para alguns pressupostos:

a) A prática como componente curricular precisa ser um exercício de imersão na cultura escolar ou de espaços educativos não escolares. Os licenciandos, independentemente dos componentes disciplinares, precisam experimentar a formação in loco, com todas as suas vicissitudes. É preciso espaços formativos em que a teoriaprática se movimentem;

b) É necessário que haja convergências e divergências argumentadas entre os conhecimentos teórico-metodológicos dos professores do curso de Pedagogia da UESB e a cultura escolar e em outras ambiências educativas, a fim de que a formação escape das lógicas "aplicacionistas" em direção às lógicas mais "problematizadoras";

c) A formação de professores não pode estar direcionada à natureza teórica e técnica instrumental, mas precisa considerar a multiplicidade das dimensões do/no cotidiano escolar, em que o ensino, a pesquisa e a extensão suplementem o instituído, produzindo práticas curriculares mais potentes e criativas;

d) A PP é um espaço potente de interação dialógica e de participação coletiva como forma de acentuar a compreensão da função social da profissão;

É inegável que o cotidiano de uma profissão não se aprende e apreende por ter acesso aos textos legais e ao aporte teórico. É por isso que argumentamos em defesa da prática como um modo de pensar, de agir, de resistir. Falamos de um cotidiano que as escrituras dos projetos pedagógicos de cursos e das escolas de modo geral não alcançam; e, se o alcançassem, poderia ser intraduzível. Situações de reprovação, repetência, 
abandono escolar, não domínio ou o domínio inadequado da lectoescrita, restrições no desenvolvimento do pensamento lógico-matemático, racismo estrutural, bullying, sexualidade, questões de gênero, violência doméstica, necessidades educacionais especiais, entre outras demandas socioculturais constituem-se como elementos comuns aos processos de exclusão que têm marcado os atores sociais da educação escolar e não escolar. Esses aspectos, entre tantos outros, podem ser problematizados pelos estudantes através da PP, em movimentos de autoria e de autorização tanto na escolha de suas itinerâncias formativas, quanto nas opções teórico-metodológicas, a partir de uma rigorosa e autônoma produção de conhecimentos aliada a efetiva orientação docente.

\section{Considerações (não) Finais}

Ao longo desse trabalho fizemos um esforço em problematizar os contextos de produção das políticas públicas para a formação de professores no Brasil; discutir as traduções curriculares decorrentes das políticas de Estado para essa formação; e apresentar uma proposição para a prática como componente curricular (PCC), em atendimento à Resolução CNE 02/2015, documento que defendemos como principal ancoragem para a formação de professores brasileiros atualmente.

Ao discutirmos a prática como componente curricular, cuidamos de afirmá-la em sua indissociabilidade com a teoria, por isso assumimos a unidade teoriaprática em todo o texto, a fim de marcar um posicionamento político em que a prática se traduz como espaço de luta contra o poder, como nos diz Foucault em conversa com Deleuze (DELEUZE, 2006). Assim posto, resistimos às logicas formativas que veem na prática um território de aplicação e imprimem uma natureza meramente instrumental. Assim, nos somamos às vozes que tensionam em direção a revogação da Resolução $\mathrm{CNE} / \mathrm{CP}$ n.02/2019, por esta induzir a uma separação grosseira entre a gestão e a docência no curso de Pedagogia, além do visível silenciamento da pesquisa como princípio formativo. Decorre daí a nossa proposição de uma arquitetura curricular em que a docência e a gestão em espações escolares e não escolares sejam postas como interfaces na formação do pedagogo.

Em nossas proposições as PCC - chamada de Pesquisa e Prática (PP) - emergem como eixos articuladores da proposição curricular, alimentadas pelos Núcleo de Estudos, Pesquisa e Extensão (NEPE), a fim de reafirmar que a formação do pedagogo não pode prescindir da pesquisa. São traduções curriculares em que nos autorizamos a "corromper" os discursos legais instituintes de práticas curriculares esvaziadas do sentido político 
Daniele Farias Freire Raic, Maria Roseli Gomes Brito de Sá, Sirlândia Souza Santana e Ubirajara Couto Lima

da/na formação de professores no Brasil. Defender a prática em sua potência formativa é, para nós, uma atitude política face ao desmonte das políticas comprometidas com uma educação de qualidade social.

\section{Referências}

BAHIA. Conselho Estadual de Educação. Resolução CEE $n^{\circ} 70$, de 16 de julho de 2019. Regulamenta a implantação das Diretrizes Curriculares Nacionais para a Formação Inicial em Nível Superior, nos Cursos de Graduação de Licenciatura, mantidos pelas instituições de ensino superior integrantes do Sistema Estadual de Ensino da Bahia. Disponível em: http://www.conselhodeeducacao.ba.gov.br/arquivos/File/ Resolucao_e_Parecer_CEE.pdf . Consultado em 20 de março de 2020.

BALL, S. J.; BOWE, R. Subject departments and the "implementation" of National Curriculum policy: an overview of the issues. Journal of Curriculum Studies, London, v.
24,
2 ,
97-115,
1992.
Disponível
em

https://www.researchgate.net/profile/Stephen_Ball6/publication/248986176_Subject_D epartments_and the Implementation_of_National_Curriculum_Policy_An_Overview of the Issues/links/54634f2b0cf2c0c6aec360b9/Subject-Departments-and-theImplementation-of-National-Curriculum-Policy-An-Overview-of-the-Issues.pdf. Consultado em 15 de fevereiro de 2021.

BERNSTEIN, Basil. A pedagogização do conhecimento: estudos sobre recontextualização. Cadernos de Pesquisa, São Paulo, n. 120, p. 75-110, nov. 2003.

BRASIL. Conselho Nacional de Educação. Parecer CNE/CES $N^{o}$ 15/2005. Responde à solicitação de esclarecimento sobre as Resoluções CNE/CP $n^{\circ}$ s 1/2002, que institui Diretrizes Curriculares Nacionais para a Formação de Professores da Educação Básica, em nível superior, curso de licenciatura, de graduação plena, e 2/2002, que institui a duração e a carga horária dos cursos de licenciatura, de graduação plena, de Formação de Professores da Educação Básica, em nível superior. Disponível em: http://portal.mec.gov.br/cne/arquivos/pdf/pces0015_05.pdf. Consultado em $11 \mathrm{de}$ novembro de 2020.

BRASIL. Conselho Nacional de Educação. Resolução CNE/CP $n^{o}$ 02, de 01 de julho de 2015. Define as Diretrizes Curriculares Nacionais para a formação inicial em nível superior (cursos de licenciatura, cursos de formação pedagógica para graduados e cursos de segunda licenciatura) e para a formação continuada. Disponível em http://portal.mec.gov.br/docman/agosto-2017-pdf/70431-res-cne-cp-002-03072015pdf/file . Consultado em 20 de março de 2020.

BRASIL. Conselho Nacional de Educação. Resolução CNE/CP $n^{o}$. 02, de 20 de dezembro de 2019. Define as Diretrizes Curriculares Nacionais para a Formação Inicial de Professores para a Educação Básica e institui a Base Nacional Comum para a Formação 
Inicial de Professores da Educação Básica (BNC-Formação). Disponível em: http://portal.mec.gov.br/docman/dezembro-2019-pdf/135951-rcp002-19/file

Consultado em 02 de fevereiro de 2020.

CRUZ, Gisele B. da. Curso de Pedagogia no Brasil: história e formação com pedagogos primordiais. Rio de Janeiro: Wak Editora, 2011.

DELEUZE, Gilles. A ilha deserta. Edição preparada por Davi Lapoujade. Organização brasileira e revisão técnica Luiz Orlandi. São Paulo: Iluminura, 2006.

DELEUZE, Gilles. Conversações. $3^{a}$ Edição. Tradução de Peter Pál Pelbart. São Paulo: Editora 34, 2013.

DERRIDA, Jacques. Torres de Babel. Trad. Júnia Barreto. Belo Horizonte: Editora UFMG, 2002.

DOURADO, Luiz. Diretrizes curriculares nacionais para a formação inicial e continuada dos profissionais do magistério da educação básica: concepções e desafios. Educ. Soc. vol.36 no.131 Campinas Apr./June 2015. Disponível em: https://www.scielo.br/scielo.php?script=sci_arttext\&pid=S0101-73302015000200299.

Consultado em 02 de fevereiro de 2021.

LOPES, Alice Casimiro; CUNHA, Érika V. R. da; COSTA, Hugo Heleno C. Da recontextualização à tradução: investigando políticas de currículo. Currículo sem Fronteiras, v. 13, n. 3, p. 392-410, set./dez. 2013. Disponível em: https://www.curriculosemfronteiras.org/vol13iss3articles/lopes-cunha-costa.pdf

Consultado em 20 de janeiro de 2021.

LOPES, Alice. C. Teorias Pós-Críticas, Política e Currículo. Educação, Sociedade \& Culturas, $\mathrm{n}^{\mathrm{o}}$ 39, 2013, 7-23. Disponível em: https://www.fpce.up.pt/ciie/sites/ default/files/02.AliceLopes.pdf . Consultado em 20 de janeiro de 2021.

MAINARDES, J. Abordagem do ciclo de políticas: uma contribuição para a análise de políticas educacionais. Educ. Soc., Campinas, vol. 27, n. 94, p. 47-69, jan./abr. 2006. Disponível em: http://www.scielo.br/pdf/es/v27n94/a03v27n94.pdf . Consultado em 03 de janeiro de 2021.

SAVIANI, Dermeval. Pedagogia: o espaço da educação na universidade. Cadernos de Pesquisa, v. 37, n. 130, jan./abr. 2007. Disponível em: https://www.scielo.br/pdf/cp/v37n130/06.pdf . Consultado em 15 de dezembro de 2019.

SILVA, Carmem Silvia B. Da. Curso de Pedagogia no Brasil: História e Identidade. $3^{\mathrm{a}}$ Edição. Campinas, SP: Autores Associados, 2006 (Coleção Polêmicas do nosso tempo; 66).

Recebido em: 21 jan. 2021. 
Daniele Farias Freire Raic, Maria Roseli Gomes Brito de Sá, Sirlândia Souza Santana e Ubirajara Couto Lima

Aprovado em: 13 jul. 2021.

* Daniele Farias Freire Raic é Professora Adjunta da Universidade Estadual do Sudoeste da Bahia (UESB). Docente do Programa de Pós-graduação em Educação (Ppged-UESB). Líder do Grupo de Estudos em Formação, Políticas e Práticas Educativas e Curriculares (Geforppec/CNPq). Membro do Grupo de Pesquisa em Formação em Exercícios de Professores (FEP/CNPq/ UFBA). Mestre e Doutora em Educação pela Universidade Federal da Bahia (UFBA); em conclusão de estudos pós-doutorais na mesma Universidade.

E-mail: danielefreire.uesb@gmail.com

Orcid: https://orcid.org/0000-0002-1137-736X

** Maria Roseli Gomes Brito De Sá é Professora Associada da Universidade Federal da Bahia (UFBA). Docente dos Programas de Pós-graduação em Educação da UFBA: PGEDU e PPGCLIP/ MPED. Líder do Grupo de Pesquisa Formação em Exercícios de Professores (FEP/CNPq/ UFBA). Membro do Grupo de Estudos em Formação, Políticas e Práticas Educativas e Curriculares (Geforppec/CNPq-UESB). Mestre e Doutora em Educação pela Universidade Federal da Bahia (UFBA). Pós-doutora em Desenvolvimento curricular pela Universidade do Minho - PT.

E-mail: roselisa.rds@gmail.com

Orcid http://orcid.org/0000-0002-5457-1074

*** Sirlândia Souza Santana é Professora Adjunta da Universidade Estadual do Sudoeste da Bahia (UESB). Pesquisadora das relações étnico-raciais e de gênero na escola vinculada ao Grupo de Estudos em Teorias do Discurso (Geted-UESB. Coordena a linha de pesquisa Cultura, Etnia, Gênero e Práxis Pedagógica. Mestra e doutora (2015) em Ciências Sociais pela Pontifícia Universidade Católica de São Paulo-PUC/SP.

E-mail: sirlandiasantana@hotmail.com

Orcid: https://orcid.org/0000-0002-4117-5590

**** Ubirajara Couto Lima é Professor Assistente da Universidade Estadual do Sudoeste da Bahia (UESB). Pesquisador do Grupo de Pesquisa Federalismo e Políticas Educacionais, da Universidade Federal do Espírito Santo (UFES) e do Grupo de Estudos em Formação, Políticas e Práticas Educativas e Curriculares (GEFORPPEC/CNPq). Coordenador do Observatório da Educação Básica (OEB). Mestre em Educação pela Universidade Federal da Bahia (UFBA) e doutorando em Ciências da Educação no Programa Doutoral em Ciências da Educação da Universidade do Porto, PT.

E-mail: bira.lima@hotmail.com

Orcid: https://orcid.org/0000-0002-7550-0494 